\title{
A GESTÃO DE RESÍDUOS DA CONSTRUÇÃO CIVIL NO MUNICÍPIO DE SOROCABA-SP
}

\section{Management wast from construction in the city of Sorocaba}

\author{
Daniel Bertoli Gonçalves ${ }^{1}$ \\ Recebido em 21 de maio de 2015; recebido para revisão em 18 de janeiro de 2015; aceito em 20 de fevereiro de \\ 2016; disponível on-line em 22 de março de 2016.
}

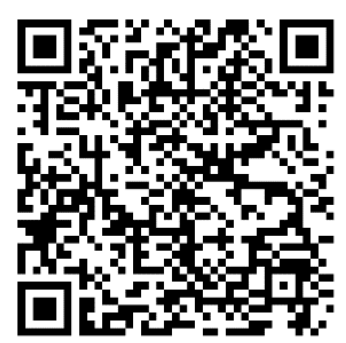

PALAVRAS CHAVE:

Resíduos de construção;

Construção civil;

Gestão de resíduos;

Sustentabilidade;

Ambiente.

\section{KEYWORDS:}

Demolition waste;

Construction;

Waste management;

Sustainable engineering;

Environment.

\section{* Contato com os autores:}

${ }^{1}$ e-mail: daniel.goncalves@prof.uniso.br ( D. B. Gonçalves )

RESUMO: O setor da construção civil, apesar da inegável importância para o desenvolvimento econômico e social do Brasil, tem sido apontado como um dos maiores geradores de impactos ambientais, seja pelo consumo significativo de recursos naturais não renováveis, seja pela intensa geração de resíduos, cuja destinação nem sempre é adequada. Nesse trabalho avaliou-se a gestão dos Resíduos da Construção Civil e Demolição (RCD) no município de Sorocaba-SP, em aspectos como quantidades produzidas, composição, áreas de descartes irregulares e impactos ambientais causados, de modo a verificar se o modelo de gestão proposto pelo município está de acordo com as leis e normas vigentes, com destaque para a resolução no 307 do CONAMA (2002) e a Lei 12.305 (BRASIL, 2010) que estabeleceu a Política Nacional de Resíduos Sólidos. Observou-se que apesar de ainda estar em atraso na implementação de um plano municipal de gestão de resíduos, o poder público local vem realizado algumas ações no sentido de adequar a destinação de seus resíduos as leis e normas ambientais vigentes. A implantação de "ecopontos" de coleta, o beneficiamento e a utilização dos resíduos processados nas obras públicas merece destaque pela economia dos recursos públicos e pelo destino ambientalmente mais adequado desses matérials, que seriam descartados em aterros, contribuindo para a redução dos impactos ambientais no município. Frente ao debate sobre a sustentabilidade ambiental da construção civil, medidas como a coleta e reutilização de resíduos oriundos de recursos naturais não renováveis, demonstram ser promissoras, e apontam um caminho para estudos mais aprofundados.

\begin{abstract}
The construction sector, one of the most important for economic and social development of Brazil, is a major generator of environmental impacts, either by significant consumption of natural resources, or the massive generation of waste. There are several consequences of the large volume of Construction Demolition Waste (CDW) generated in large urban centers. This article demonstrates the results of a study of the situation of the management of CDW in Sorocaba-SP, Brazil, in areas such as production quantities, composition, areas of irregular discharges and caused environmental impacts. At the end, it is checked whether the model waste management proposed by the municipality complies with the laws and regulations, taking into account the 307 CONAMA (2002) Resolution and Law 12,305 that establishing the National policy of solid waste (2010), which results in the recycling and / or reuse of waste; transport and deposition in the correct locations. It was observed that although still behind schedule in implementing a municipal waste management plan of the local government has carried out some actions to suit the destination of their waste current laws and environmental regulations. The implementation of "ecopoints" to the collection, processing and use of waste in public works resulted in public resource-saving and environmentally sound manner, without it would be disposed of in landfills, contributing to the reduction of environmental impacts. At the debate on the environmental sustainability of construction, measures such as the collection and reuse of waste from non-renewable natural resources, prove to be promising, and point the way for further study.
\end{abstract} \footnotetext{
Ambientais da Universidade de Sorocaba.

Doutor em Engenharia de Produção, Docente do curso de Engenharia Civil e do Mestrado em Processos Tecnológicos e
} 


\section{INTRODUÇÃO}

O aumento das atividades de construção civil no Brasil tem contribuído com o aumento do consumo de energia, água e recursos naturais, além de contribuir com o aumento do volume dos resíduos sólidos dispostos no meio ambiente, provocando grande impacto ambiental.

Quando não gerenciados adequadamente, os Resíduos da Construção Civil e Demolição (RCD) acabam depositados em rios, logradouros públicos, vias e locais irregulares, comprometendo a qualidade de vida urbana e a paisagem, contribuindo com a proliferação de vetores de doenças e com a degradação urbana de pequenas e grandes cidades (KARPINSK, et al., 2009).

Segundo a associação brasileira de empresas de limpeza pública e resíduos especiais ABRELPE, em torno de $50 \%$ de todo resíduo gerado no Brasil é proveniente das atividades de construção e demolição (MARQUES NETO, 2005).

Em 2002 entrou em vigor a resolução 307 do Conselho Nacional do Meio Ambiente (CONAMA), que estabelece critérios e diretrizes para procedimentos de gestão de resíduos da construção civil, e em 2010 a Lei no 12.305, que institui a Política Nacional de Resíduos Sólidos (PNRS), instituindo a responsabilidade compartilhada dos geradores de resíduos. (BRASIL, 2010)

Essa legislação estabelece diretrizes, critérios e procedimentos para a gestão dos resíduos da construção civil, disciplinando as ações necessárias de forma a minimizar os impactos ambientais, e tornando obrigatória a criação de Planos Integrados de Gerenciamento dos Resíduos nos municípios, incluindo a questão dos resíduos de construção civil e demolição (ARAÚJO, et al., 2006).

Encontrar soluções para a redução dos impactos ambientais das atividades desenvolvidas pelo setor de construção civil mostra-se, portanto, de fundamental importância para a promoção de um desenvolvimento sustentável mais amplo, em especial nos aspectos ambientais relacionados ao uso racional de recursos, e ao descarte de resíduos.

\section{OBJETIVO}

Este trabalho avaliou a gestão dos Resíduos da Construção Civil e Demolição (RCD) no município de Sorocaba-SP, em aspectos como quantidades produzidas, composição, áreas de descartes irregulares e impactos ambientais causados, de modo a verificar se o modelo de gestão adotado no município está de acordo com as leis e normas vigentes, com destaque para a resolução no 307 (CONAMA, 2002) e a Lei 12.305 (BRASIL, 2010) que estabeleceu a Política Nacional de Resíduos Sólidos, assim como sua contribuição para a sustentabilidade ambiental da Construção Civil no município.

\section{RESÍDUOS DA CONSTRUÇÃO CIVIL E DEMOLIÇÃO}

Os resíduos sólidos da construção e demolição (RSCD) são aqueles gerados nos canteiros de obras, provenientes de construções, reformas e demolições, como os tijolos, blocos cerâmicos, concreto em geral, etc. Os RSCD são as sobras do processo construtivo (BLUMENSCHEIN, 2007).

A disposição final desses resíduos está ficando mais complicada a cada dia, devido aos gastos com transporte e à dificuldade em encontrar as áreas que atendam às exigências ambientais.

\subsection{PRINCIPAIS CARACTERÍSTICAS DOS RESÍDUOS DA CONSTRUÇÃO CIVIL}

De acordo com a norma NBR 10.004 (ABNT, 2004), os resíduos da construção civil são classificados na classe II b - Inertes, e são definidos como:

"Quaisquer resíduos que, quando amostrados de forma representativa, submetidos a um contato estático ou dinâmico com água destilada ou deionizada, à temperatura ambiente, conforme teste de solubilização, não tiverem nenhum de seus constituintes solubilizados em concentrações superiores aos padrões de potabilidade de água, excetuando-se os padrões de aspecto, cor, turbidez, e sabor. Como exemplo destes materiais, podem-se citar rochas, tijolos, vidros e certos plásticos $e$ borrachas que não são decompostos prontamente." NBR 10.004 (ABNT, 2004). 
Porém, a resolução no 307 (CONAMA, 2002) e a Lei 12.305 (BRASIL, 2010), definem os RCD como materiais provenientes de construções, reformas, reparos, demolições e escavações ou preparação de terrenos de obras de construção civil, denominados como entulhos de obras.

A gestão dos RCD deve ser de responsabilidade do município e do setor gerador. Para saber a disposição final dos resíduos, bem como o gerenciamento do mesmo, é preciso saber a sua classificação. De acordo com as resoluções $\mathrm{n}$ ㅇ 432 e no 448 (CONAMA, 2011 e 2012), os RCD são classificados da seguinte forma:

- Classe A - são os resíduos reutilizáveis ou recicláveis como agregados, componentes cerâmicos, argamassa e concreto. Deposição: Deverão ser reutilizados ou reciclados na forma de agregados, ou encaminhados aterros de resíduos onde possam ser reservados para utilização futura;

- Classe B - são os resíduos recicláveis para outras destinações, tais como: plásticos, papel/papelão, metais, vidros, madeiras e gessos. Deposição: Deverão ser reutilizados, reciclados ou encaminhados a áreas de armazenamentos temporários, sendo dispostos de modo a permitir a sua utilização ou reciclagem futura;

- Classe C - são os resíduos para os quais não foram desenvolvidas tecnologias ou aplicações economicamente viáveis que permitam a sua reciclagem/recuperação. Deposição: deverão ser armazenados, transportados e destinados em conformidade com normas técnicas específicas;

- Classe D - são os resíduos perigosos como tintas, solventes, óleos ou aqueles contaminados ou prejudiciais à saúde. Deposição: deverão ser armazenados, transportados, e destinados em conformidade com normas técnicas.

Conforme Marques Neto (2005), praticamente todas as atividades desenvolvidas no setor da construção civil são geradores de RCD, e o seu alto e polêmico índice de perdas é a principal causa dos resíduos.
Separar os resíduos de acordo com a sua classe, desde o início da obra, é uma atividade dinâmica que leva certo tempo. Dependendo da etapa em que está a obra (fundação, estrutura, alvenaria ou acabamento), o volume da geração do resíduo de cada tipo de sua classe, divergem muito.

Essa separação é demorada pelo fato do RCD ser gerado no setor onde existem diferentes métodos de produção. Dessa forma, a caracterização média deste resíduo está condicionada a parâmetros específicos da região geradora do resíduo analisado (ZORDAN, 1997).

Em análises feitas no aterro de Itatinga, São Paulo, Brito Filho (1999) destacou a composição média dos entulhos, conforme pode ser visto na Figura 1.

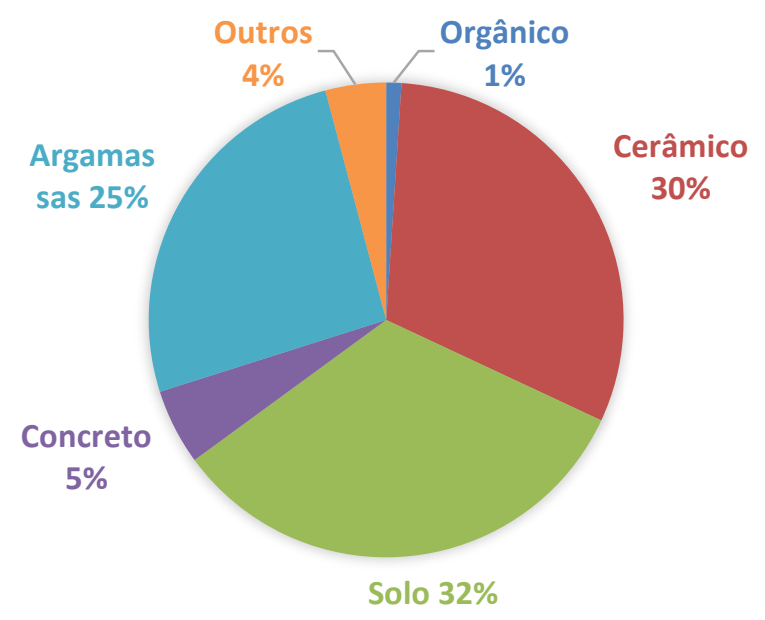

FIGURA 1: Composição média dos entulhos depositados no aterro de Itatinga, São Paulo.

FONTE: BRITO FILHO (1999).

De acordo com John e Agopyan (2000) os resíduos de construção são constituídos de uma ampla variedade de produtos, que podem ser classificados em:

"Solos; Materiais "cerâmicos": rochas naturais, concreto, argamassas a base de cimento e cal, resíduos de cerâmica vermelha, como tijolos e telhas, cerâmica branca, especialmente a de revestimento, cimento-amianto, gesso - pasta e placa, vidro; e Materiais metálicos, como aço para concreto armado, latão, chapas de aço galvanizado, etc.; Materiais orgânicos: como madeira natural ou industrializada, plásticos diversos, materiais betuminosos, tintas $e$ adesivos, papel de embalagem, restos de vegetais e outros produtos de limpeza de terrenos." (JOHN e AGOPYAN, 2000). 
Com o adensamento urbano das grandes cidades metrópoles já existem diversas soluções para a valorização dos entulhos da construção civil. Equipamentos portáteis podem ser levados nas obras, triturando os entulhos selecionados, gerando agregados para serem utilizados em concretos não estruturais (FERREIRA, 2012).

\subsection{IMPACTOS AMBIENTAIS E OS AVANÇOS DA LEGISLAÇÃO}

No Brasil, estima-se que, para cada tonelada de lixo urbano recolhido, são coletadas duas toneladas de entulho originado do setor de construção civil (MARQUES NETO, 2005).

Boa parte dos profissionais que atuam na construção civil desconhece a quantidade de RCD que produzem e, quando compreendem a poluição ambiental que estão provocando, não estão orientados dos passos necessários para fazer uma destinação correta dos resíduos, que podem simplesmente ser separados e reutilizados na própria obra ou ser encaminhados para processos de reciclagem externos. Práticas muito importantes para o meio-ambiente, que estão diretamente relacionadas com a redução dos impactos ambientais gerados pelo setor (MARINHO e SILVA, 2012).

Da mesma forma, programas de redução de perdas nas etapas da construção e gestão para a correta deposição dos resíduos contribuem para reduzir a geração do RCD (CARNEIRO et al., 2001).

Para ADDIS (2010), praticar o reuso, a coleta seletiva e a reciclagem dos resíduos, trazem vários benefícios as construtoras, como redução de custos com matéria prima, custos com o transporte de resíduos, taxas de despejo de materiais em aterro, entre outros.

Em seu trabalho, Pinto (2005) constatou que cerca de $75 \%$ dos Resíduos de Construção Civil (RCC) dos municípios vêm de obras informais e, a inexistência de políticas públicas, que disciplinam e ordenam os fluxos da destinação dos RCC, estão causando impactos ambientais como: (1) a degradação das áreas de manancial e de proteção permanente; (2) Proliferação de agentes transmissores de doenças; (3) Assoreamento de rios e córregos; (4) Obstrução dos sistemas de drenagem, tais como piscinões, galerias, sarjetas, etc.; (5) Ocupação de vias e logradouros públicos por resíduos, com prejuízo à circulação de pessoas e veículos, além da própria degradação da paisagem urbana; (6) Existência de acúmulo de resíduos que podem gerar risco por sua periculosidade.

Por causa desse crescente aumento de RCD e os impactos causados no meio-ambiente, o CONAMA formulou a resolução no 307 (CONAMA, 2002), que responsabiliza os geradores de resíduos pela destinação final dos mesmos. Sua vigência começou a partir de julho de 2002, e estabelece diretrizes, critérios e procedimentos para a gestão dos resíduos da construção civil, disciplinando as ações necessárias de forma a minimizar os impactos ambientais.

No entanto, ARAÚJO et al. (2006) alega que, por motivos diversos, a Resolução $\mathrm{n}^{\circ} 307$ (CONAMA, 2002) não atingiu seus objetivos de forma satisfatória, sendo os principais motivos, a baixa divulgação da resolução em meio as construtoras, e a consequente falta de comprometimento com sua implementação.

A partir da Lei 12.305 (BRASIL, 2010) que instituiu a Política Nacional de Resíduos Sólidos (PNRS), a responsabilidade pela gestão dos RCD estendeu-se aos Municípios e ao Distrito Federal. Para isso, deveria ser criado um Plano Integrado de Gerenciamento dos Resíduos, que incorporasse um programa municipal de gerenciamento dos $R C D$ e projetos de gerenciamento desses resíduos pelos seus geradores - Resolução no 448 (CONAMA, 2012).

Segundo a regulamentação supracitada, a elaboração de um plano municipal de gestão integrada de resíduos sólidos deve contemplar:

- A situação dos resíduos sólidos gerados, contendo a origem, o volume, a caracterização e as formas de destinação e disposição final;

- Identificação das áreas favoráveis para disposição final ambientalmente adequada;

- Possíveis soluções compartilhadas com outro município;

- Identificação dos geradores sujeitos ao plano de 
gerenciamento específico;

- Procedimentos operacionais e especificações a serem adotadas nos serviços públicos do manejo de resíduos sólidos;

- Indicadores de desempenho operacional do manejo sólidos;

- Regras para o transporte e de outras etapas do gerenciamento dos resíduos sólidos;

- Programas e ações de capacitação técnica, voltados para sua implementação e operacionalização;

- Programas e ações de educação ambiental que promovam a não geração, a redução, a reutilização e a reciclagem de resíduos sólidos;

- Metas de redução, reutilização, coleta seletiva e reciclagem, entre outras, com vistas a reduzir a quantidade de rejeitos encaminhados para disposição final ambientalmente adequada;

Ainda segundo a legislação, as empresas de construção civil deveriam elaborar um plano próprio de gerenciamento de resíduos sólidos, com um diagnóstico dos resíduos sólidos gerados, contendo a origem, o volume e a caracterização dos resíduos, incluindo os passivos ambientais a eles relacionados, mantendo atualizadas e disponíveis ao órgão municipal, informações completas sobre a implementação do plano (BRASIL, 2010).

Para a concretização de tudo isso, a PNRS estipulou prazos para os municípios, que deveriam elaborar seus Planos Municipais de Gestão até janeiro de 2013, e ainda implantados até julho do mesmo ano, de forma independente ou conjunta com outros municípios, desde que seguisse o art.14 da Lei 12.305 (BRASIL, 2010).

\section{PROCEDIMENTOS METODOLOGICOS}

\subsection{CARACTERIZAÇÃO DA ÁREA DE ESTUDO}

O município de Sorocaba-SP faz parte de uma região administrativa com 79 municípios, possui 614 mil habitantes, uma taxa de urbanização de 99\%, altíssima densidade demográfica, e gera cerca de 4.189 toneladas de RCC por dia, que corresponde a $6,13 \%$ do total gerado no estado de São Paulo (SHS, 2014).

Até meados de 2006, a maioria dos resíduos da construção civil gerada em Sorocaba era disposta no "Bolsão de Entulho do Ipatinga" (figura 2), localizado sobre o antigo lixão do município, na Estrada do Ipatinga. O Bolsão recebia uma média diária de $18.000 \mathrm{~m}^{3}$ de resíduos inertes (entulho da construção civil), sobras de madeira e material de poda de árvores e de conservação de praças e jardins. Entretanto, o local estava praticamente esgotado e não possuía Licença de Operação junto à CETESB, que havia indeferido o pedido (PREFEITURA MUNICIPAL, 2012).
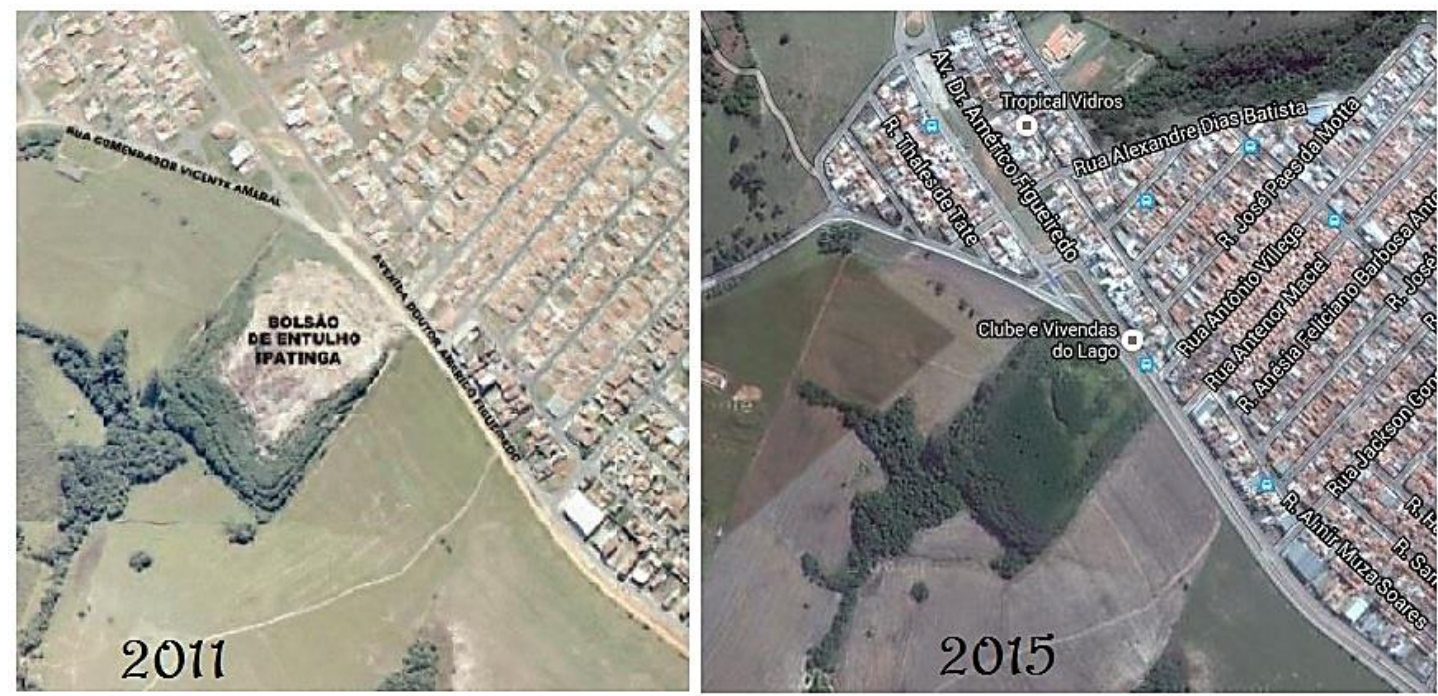

FIGURA 2: Antigo Bolsão de entulho no município de Sorocaba-SP em 2011 e 2015. FONTE: Adaptado de Sanex (2011) e Google Maps (2015). 
Visando a atender o disposto na Resolução no 207 (CONAMA, 2002) sobre a disposição dos resíduos inertes, a prefeitura de Sorocaba buscou nova área para a construção de um aterro para esses resíduos. Assim, houve a desapropriação, por meio do Decreto no 14.670 de 2005, de um imóvel situado à Avenida General Motors, no 200, Bairro Ronda Grande, na Zona Industrial (Figura 3), de aproximadamente $203 \mathrm{mil}$ metros quadrados, que seria destinado à construção de um novo aterro para RCC, com previsão de, no mínimo, 20 anos de operação (ENGECORPS, 2111).

No mesmo ano foi firmado um Termo de Ajustamento de Conduta (TAC) entre a prefeitura e o Ministério Público do Estado de São Paulo para o início imediato da utilização do aterro de inertes. Entre as obrigações acordadas estava a apresentação de um Relatório Ambiental Preliminar (RAP), entregue em dezembro de 2006, juntamente com um Plano de Recuperação de Áreas Degradadas (PRAD) para o local onde seria implantado o novo aterro de inertes, visto que o local encontrava-se degradado por ter sido utilizado anteriormente para exploração de argila.

Em 2011, foi contratada uma empresa especializada, através da Secretaria de Saneamento e Recursos Hídricos do Estado de São Paulo (SSRH), para elaborar uma proposta para um Plano Municipal Integrado de Saneamento Básico para o Município de Sorocaba, englobando o abastecimento de água potável, esgotamento sanitário, drenagem e manejo de águas pluviais, limpeza urbana e manejo de resíduos sólidos, e integrado ao Plano Regional de Saneamento Básico (PRSB), levando em consideração a lei federal $\quad \mathrm{n} 011.445$ de 05 de janeiro de 2007 (BRASIL, 2007).

Nesse plano, a solução para redução de resíduos sólidos inertes seria a separação das ferragens para sua reciclagem, enquanto que o restante de concreto, terra, tijolos e pedras, poderiam ser submetidos ao processo de britagem, resultando em material passível de ser reutilizado na construção civil. Com essa proposta, Sorocaba aproveitaria até $60 \%$ dos resíduos sólidos inertes até o ano de 2015, atendendo o prazo fixado na legislação para a reciclagem máxima até o final de quatro anos (ENGECORPS, 2011).

No entanto, até o início de 2015 a Prefeitura Municipal de Sorocaba ainda não havia aprovado seu Plano Municipal de Gestão Integrada de Resíduos Sólidos (PMGIRS), o qual ainda se encontrava em estudos pela Câmara de Vereadores e pela Secretaria do Meio Ambiente do Município de Sorocaba (SEMA).

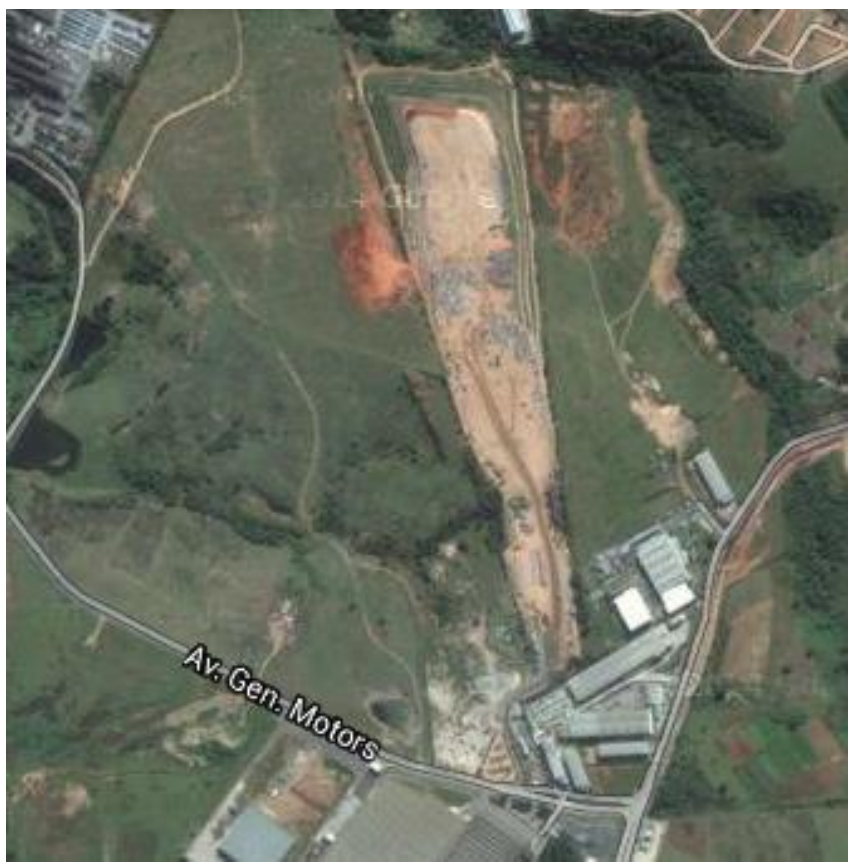

FIGURA 3: Vista do aterro de Inertes do município de Sorocaba-SP. FONTE: Google maps (abril, 2015). 


\subsection{TIPO DE ESTUDO}

O presente estudo utilizou uma abordagem qualitativa e quantitativa, com pesquisa de caráter exploratório descritivo, sustentada em base de dados bibliográficos e visitas in loco.

Segundo Gil (2002), a pesquisa exploratória tem por objetivo aproximar-se do tema, criando maior familiaridade em relação ao fato ou fenômeno.

De acordo com Cervo et. Al (2007), a pesquisa descritiva, observa, registra, analisa e correlaciona fatos ou fenômenos variáveis, sem manipulá-los. Procura descobrir, com a maior precisão possível, a frequência com que um fenômeno ocorre, sua relação e conexão com outros, sua natureza e características. Dessa forma, busca conhecer as diversas situações e relações que ocorrem na vida social, política, econômica e demais aspectos, do comportamento humano, tanto do indivíduo tomado isoladamente como de grupos e comunidades mais complexas.

Enquanto a primeira fase caracterizou-se por um levantamento de dados bibliográficos na literatura disponível, em relatórios técnicos e no site da prefeitura de Sorocaba-SP, a segunda fase envolveu visitas in loco nos pontos de coleta e locais de descarte de resíduos de construção, bem como reuniões com gestores públicos do município de Sorocaba, entre agosto de 2013 e dezembro de 2014, visando identificar o fluxo dos resíduos, o funcionamento do aterro municipal de Inertes, e as ações adotadas dentro do programa de gestão de Resíduos da Construção Civil e Demolição (RCD) no município de Sorocaba-SP.

\subsection{TÉCNICAS DE COLETA E ANÁLISE DE DADOS}

A fim de verificar se o modelo de gestão de RCD adotado no município de Sorocaba-SP estava de acordo com as leis e normas vigentes, foram realizadas visitas "in loco", registros fotográficos, anotações de observações realizadas durante as visitas aos locais de coleta e ao aterro de inertes, e anotações de observações durante as entrevistas com gestores municipais, e visitas técnicas a locais de coleta e ao aterro de inertes.

\section{RESULTADOS E DISCUSSÕES}

Segundo informações obtidas na pesquisa, a prefeitura municipal de Sorocaba-SP procurou se adequar à Política Nacional de Resíduos Sólidos através da criação de um Plano Municipal de Gestão Integrada de Resíduos Sólidos, do qual faz parte o Plano de Gerenciamento de Resíduos da Construção Civil, o qual estabeleceu critérios e procedimentos para a coleta, disposição final e reaproveitamento dos resíduos de construção e entulhos de demolição provenientes de obras públicas e particulares realizadas dentro de seu perímetro municipal.

Um diferencial observado na gestão de RCD adotada no município de Sorocaba-SP é a divisão dos geradores de resíduos em dois grupos de acordo com o volume descartado, denominados pequenos e grandes geradores. Tal divisão leva em conta o volume de $1 \mathrm{~m}^{3}$ ou $50 \mathrm{~kg}$ diários (considerados como média mensal) de entulho de construções como limite para os pequenos geradores.

Enquanto os "grandes geradores", que produzem mais de $1 \mathrm{~m}^{3}$, precisam elaborar seu próprio Plano de Gerenciamento de Resíduos Sólidos e providenciar o transporte e a destinação correta dos resíduos por conta própria, aos "pequenos geradores" são oferecidos serviços de coleta pública, através de caçambas distribuídas em pontos estratégicos da cidade, denominadas "ecopontos", onde o gerador pode colocar o entulho de sua obra, com o limite de 1 metro cúbico por gerador (Figura 4).

Além da sinalização e disponibilização das caçambas, a prefeitura também arca com o transporte dos resíduos até o Aterro de Inertes do município, de duas a cinco vezes por semana, de acordo com a demanda local.

Os Ecopontos são instalados e gerenciados pela administração municipal ou pela iniciativa privada, e possuem o objetivo de minimizar os despejos de entulho em locais impróprios, como nos fundos de vale e córregos, terrenos baldios e vias públicas. Os lugares para implantação dos Ecopontos foram estabelecidos prioritariamente em áreas públicas em cujas 
imediações há maiores quantidades de construções, considerando zonas homogêneas em que já era depositado entulho. No entanto, também podem ser escolhidas áreas privadas cedidas à administração municipal com a apresentação de documentação jurídica legalmente estabelecida, instalando Ecopontos preferencialmente em locais de deposição irregular.

Até a data da pesquisa existiam 21 Ecopontos no município, totalizando 75 caçambas, onde era produzida uma média de $9.046 \mathrm{~m}^{3}$ de resíduos por mês. Em 2012, o volume total de RCD depositados nas caçambas dos Ecopontos foi de $109.898 \mathrm{~m}^{3}$ (SHS, 2014). Até 2016 está prevista a implantação de mais 14 Ecopontos, dos quais dois estarão localizados na Zona Oeste, com oito caçambas; sete na Zona Norte, com 28 caçambas; quatro nas Zonas Sudeste/Leste, com 16 caçambas; e um na Zona Sudeste, com 4 caçambas.

Segundo informações obtidas em entrevistas junto aos gestores, através desses Ecopontos, a prefeitura buscou diminuir o número de aterros irregulares e, ao mesmo tempo, conscientizar o gerador para o descarte correto dos resíduos, através de placas de sinalização e de educação ambiental.

Apesar das orientações quanto ao que se pode ou não dispor nas caçambas constarem nas placas de sinalização, nas visitas in loco foi possível constatar a ineficácia desta estratégia, pois quase todos os ecopontos continham

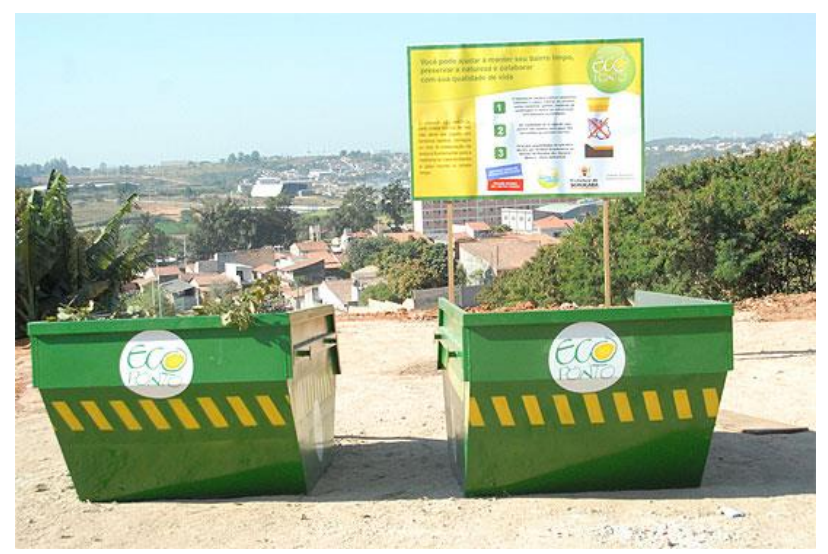

FIGURA 4: EcoPonto no município de Sorocaba-SP. FONTE: O autor (2014).
Resíduos orgânicos, plásticos e demais materiais que não se enquadravam entre os resíduos de construção e demolição. Além disso, não foi evidenciado qualquer tipo de fiscalização nos locais de descarte, e muito resíduo acumulado ao redor das caçambas (Figura 5).

Segundo informações do Plano de Gerenciamento, após a coleta nos Ecopontos, os resíduos são encaminhados por caminhões da prefeitura ao aterro de inertes municipal. Em visita in loco, observou-se que já no aterro os resíduos seguem para uma Usina de Triagem e Reciclagem de Resíduos da Construção Civil, operada pela Cooperativa de Egressos de Sorocaba e Região (COOPERESO) em parceria com o poder público municipal, que está localizada dentro do aterro de inertes municipal. Segundo informações reunidas durante entrevistas com os gestores, a usina (figura 6) foi inaugurada em 2008 a partir da parceria com empresas da região, que cederam em comodato duas máquinas, uma trituradora de entulho e uma recicladora de galhos. Em 2014 a Secretaria de Serviços Públicos (SERP) da Prefeitura de Sorocaba adquiriu uma nova máquina de moagem de entulhos, dobrando a capacidade de produção de bica corrida, um material que é usado, sobretudo, na manutenção de estradas de terra do município. Em dezembro do mesmo ano o poder público desapropriou uma área de $153 \mathrm{mil} \mathrm{m}^{2}$, anexa ao aterro de inertes, para aumentar a capacidade de armazenamento no local.

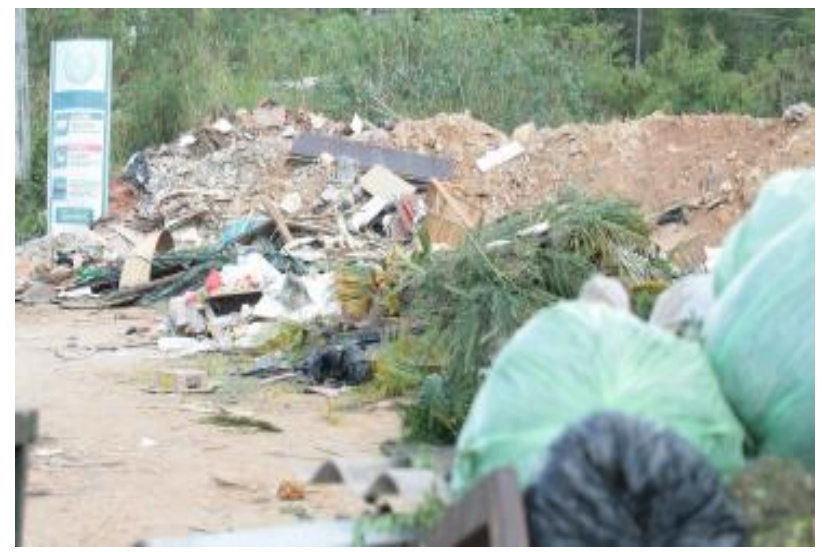

FIGURA 5: EcoPonto com acumulo de lixo no município de Sorocaba-SP. FONTE: O autor (2014). 


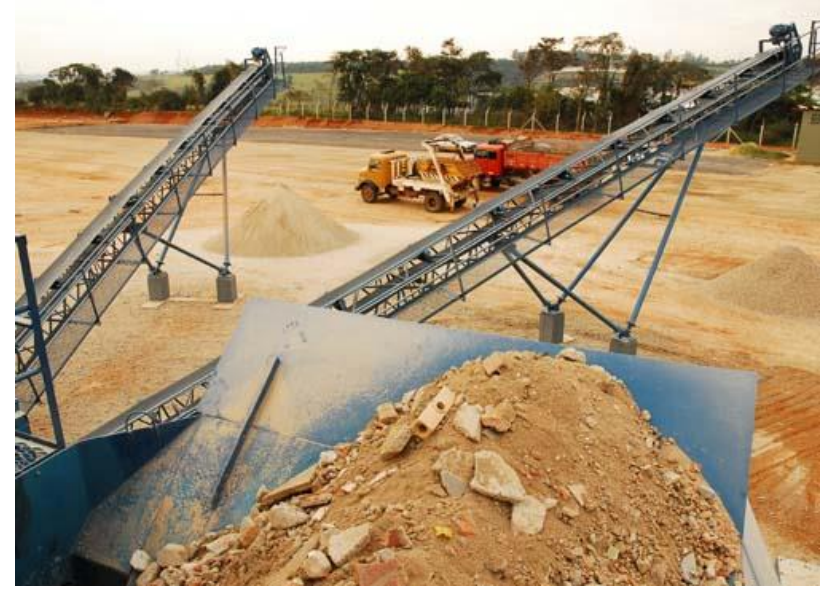

FIGURA 6: Usina de Reciclagem de Resíduos da Construção Civil de Sorocaba-SP.

FONTE: ENGECORPS (2011).

Nesta usina, o material proveniente das caçambas de Ecopontos e caçambas particulares passa inicialmente por um processo de triagem, que consiste na separação dos resíduos em três grupos: os resíduos de construção e demolição, que são encaminhados para britagem ou aterro, os materiais recicláveis, como metais, pvc, plásticos, madeiras, vidros etc, e que são estocados em caçambas metálicas e depois comercializados pela cooperativa; e os inservíveis, que estão misturados com lixo orgânico, e que são segregados em outras caçambas fechadas e levados para o aterro de Sanitário.

No caso dos grandes geradores de RCD, que no município são responsáveis por elaborar seus próprios Planos de Gerenciamento de Resíduos e providenciar o transporte e a destinação adequada, o poder público municipal buscou regulamentar o conjunto das atividades privadas que incluem todas as etapas envolvidas na operação dessas grandes quantidades de resíduos (transporte, manejo, transformação e disposição final), além de oferecer as instalações físicas para a realização de algumas operações, e estabeleceu como destino final o aterro de inertes municipal.

Desse modo, todas as empresas envolvidas com o aluguel de caçambas e transporte de resíduos só pode operar após autorização da prefeitura municipal, o que, segundo os gestores, disciplina a movimentação e o descarte, além de ser capaz de criar um sistema de rastreamento desses resíduos, e responsabilizar os envolvidos no caso de acidentes ambientais.

Com relação ao acesso ao aterro, a Lei Municipal no 8.614/2008, restringe o Aterro Municipal de Inertes do município para resíduos gerados apenas em Sorocaba, de forma a evitar que municípios vizinhos enviem seus resíduos para o mesmo. No momento do recebimento desses resíduos no local, a prefeitura realiza um controle por meio da "Nota de Remessa de Resíduos". Além disso, para a aceitação dos resíduos no Aterro, um técnico do local realiza uma primeira verificação visual da carga, constatando se esta possui características compatíveis com as licenças operacionais do aterro. Em caso afirmativo, os resíduos são posteriormente basculados na área de triagem (SOROCABA, 2008).

$\mathrm{Na}$ visita in loco ao aterro, constatou-se que também são encaminhados ao aterro de inertes resíduos volumosos como móveis, madeira, colchões e pneus, que são estocados em local específico e posteriormente destinados ao aterro sanitário de Iperó, município vizinho.

$\mathrm{Na}$ Tabela 1 estão relacionadas as quantidades anuais de entulho recebido, reciclado, e aterrado, no aterro de inertes até 2013.

Nota-se que houve oscilações ao longo do tempo, porém, apesar de a quantidade de entulho recebida no aterro ter aumentado desde 2008, a reciclagem deste resíduo não acompanhou essa tendência de crescimento. O volume de entulho aterrado, por outro lado, apresentou claramente aumento no decorrer desse período.

Para o reaproveitamento ou reciclagem, os materiais inertes passiveis de reaproveitamento são encaminhados à usina municipal de reciclagem de entulho, que produz areia, cascalho e brita de dimensões diversas, que posteriormente são utilizados em serviços de manutenção de vias de terra e pavimentação, em pavimentação em blocos articulados, em nivelamento de terrenos, e em outras obras de responsabilidade da prefeitura. 


\begin{tabular}{cccc}
\hline \multicolumn{4}{c}{ Tabela 1: Reciclagem anual de entulho no aterro de inertes de Sorocaba-SP. } \\
\hline Ano & Entulho recebido $\left(\mathrm{m}^{3}\right)$ & Entulho reciclado $\left(\mathrm{m}^{3}\right)$ & Entulho aterrado $\left(\mathrm{m}^{3}\right)$ \\
2008 & $91.109,90$ & $12.435,00$ & $64.674,90$ \\
2009 & $205.245,70$ & $16.348,29$ & $166.920,60$ \\
2010 & $336.570,40$ & $19.759,90$ & $249.975,80$ \\
2011 & $393.610,00$ & $14.748,50$ & $342.106,00$ \\
2012 & $538.144,44$ & $24.334,09$ & $420.574,87$ \\
$2013^{*}$ & $382.060,00$ & $7.674,50$ & $316.393,00$ \\
\hline
\end{tabular}

*Dados até agosto.

FONTE: Prefeitura Municipal (2013).

\section{CONCLUSÕES}

Pode-se observar que apesar do atraso em implementar o Plano Municipal Integrado de Saneamento Básico para o Município de Sorocaba, o poder público local vem realizado ações no sentido de adequar a destinação dos resíduos de construção civil e demolição as leis e normas ambientais vigentes.

A implementação dos Ecopontos de coleta pode ser considerada uma iniciativa louvável no sentido de reduzir os problemas com a destinação inadequada de pequenos volumes de resíduos, cujo destino acabava sendo os terrenos baldios e até mesmo as vias públicas nos bairros. No entanto, a implementação de um programa dessa natureza sem o envolvimento de ações de educação ambiental para a população e, sobretudo, sem a devida fiscalização, acabam atrapalhando o alcance de resultados efetivos, transformando o que deveria ser um ponto de coleta de resíduos inertes, apenas de construção e pequenas reformas, em mais um espaço para o despejo de resíduos urbanos diversos, muitos dos quais representam incômodos e riscos à população do entorno, seja pelo mal cheiro da decomposição de resíduos orgânicos e de animais mortos, seja pela proliferação de doenças e vetores, tais como insetos, aves e roedores.

Com relação ao trabalho desenvolvido dentro do aterro de inertes, pode-se destacar a iniciativa da implantação da usina de beneficiamento, e as parcerias desenvolvidas junto à iniciativa privada para a aquisição de máquinas, além do trabalho social desenvolvido através da parceria com a cooperativa de trabalhadores, que sem dúvida é um exemplo que pode ser reproduzido em outros municípios. A reutilização dos resíduos processados nas obras públicas merece destaque pela economia de recursos públicos escassos e pelo destino ambientalmente mais adequado, dados aos matérias, tornando a gestão local desses resíduos um bom exemplo de sustentabilidade econômica, social e ambiental.

Frente ao debate sobre a sustentabilidade ambiental da construção civil, medidas como a coleta e reutilização de resíduos oriundos de recursos naturais não renováveis, demonstram ser promissoras, e apontam um caminho para estudos mais aprofundados, tanto com relação ao papel do poder público e da iniciativa privada na regulação, gestão e operacionalização de ações tais como as descritas neste trabalho, quanto com relação aos possíveis usos desses materiais comumente descartados, e que podem se tornar valiosos frente à escassez de alguns recursos naturais não renováveis.

\section{AGRADECIMENTOS}

O autor agradece à FAPESP - Fundação de Amparo à Pesquisa do estado de São Paulo, pelo apoio institucional (processo no2014/21122-0).

\section{REFERÊNCIAS}

ADDIS, Bill. Reuso de materiais e elementos de construção. Oficina de Textos. São Paulo. 368p, 2010.

ARAÚJO, Nelma Mirian Chagas. et al. Gestão para os resíduos de construção e demolição (RCDs): uma proposta para a grande João Pessoa (Paraíba - Brasil). In: XII SILUBESA - Simpósio Luso Brasileiro de Engenharia 
Sanitária. (2006). Disponível em: <http://jararaca.ufsm.br/websites/ces/download/S23.PDF>. Acesso em: 12 de nov. 2013.

ASSOCIAÇÃO BRASILEIRA DE NORMAS TÉCNICAS - ABNT. NBR 10.004. Resíduos sólidos - classificação. 1998. São Paulo, Brasil.

BLUMENSCHEIN, Raquel Neves. Manual Técnico: Gestão de Resíduos Sólidos em Canteiros de Obras. Brasília: SEBRAE/DF, 2007. 48p

BRASIL. CONAMA. Resolução $\mathbf{n}^{\circ} \mathbf{3 0 7}$, de 5 de julho de 2002. Estabelece diretrizes, critérios e procedimentos para a gestão dos resíduos da construção civil. Disponível em:

http://www.mma.gov.br/port/conama/res/res02/res30 702.html>. Acesso em: 03 nov. 2013.

BRASIL. CONAMA. Resolução $n^{\circ}$ 431, de 25 de maio de 2011. Alteração da Resolução número 307/02 (Altera o inciso II e III do art. 3ㅇ). Disponível em: <http://www.mma.gov.br/port/conama/legiabre.cfm?c odlegi=649> . Acesso em: 12 nov. 2013.

BRASIL. CONAMA. Resolução $n^{\circ} \mathbf{4 4 8}$, de 18 de janeiro de 2012. Alteração da Resolução número 307/02 (Altera os arts. $2^{\circ}, 4^{\circ}, 5^{\circ}, 6^{\circ}, 8^{\circ}, 9^{\circ}, 10^{\circ}$ e $\left.11^{\circ}\right)$. Disponível em: <http://www.mma.gov.br/port/conama/res/res12/Res ol448.pdf>. Acesso em: 15 out. 2014.

BRASIL. Lei no. 11.445, de 05 de janeiro de 2007. Estabelece diretrizes nacionais para o saneamento básico; altera as Leis nos 6.766, de 19 de dezembro de 1979, 8.036, de 11 de maio de 1990, 8.666, de 21 de junho de 1993, 8.987, de 13 de fevereiro de 1995; revoga a Lei no 6.528, de 11 de maio de 1978; e dá outras providências. Disponível em: <http://www.planalto.gov.br/ccivil_03/_Ato20072010/2007/Lei/L11445.htm>. Acesso em: 15 out. 2014.

BRASIL. Lei no 12.305/10, de 12 de agosto de 2010. Institui a Política Nacional de Resíduos Sólidos; altera a Lei $\mathrm{n}$ 0 9.605, de 12 de fevereiro de 1998. Disponível em: <http://www2.camara.leg.br/legin/fed/lei/2010/lei12305-2-agosto-2010-607598-publicacaooriginal128609-pl.html>. Acesso em: 21 de maio de 2014

BRITO FILHO, Jerson A. Cidades versus entulho. In: IBRACON, ANAIS II SEMINÁRIO Desenvolvimento Sustentável e a Reciclagem na Construção Civil, Comitê Técnico CT 206 - Meio Ambiente. São Paulo, 1999, p 56 67.

CARNEIRO, Alex Pires; et al. Reciclagem de Entulho para a Produção de Materiais de Construção. Projeto entulho bom. Salvador: EDUFBA; Caixa Econômica Federal, 2001. $312 \mathrm{p}$.

CERVO, A.L; BERVIAN,P.A; SILVA, R. Metodologia Cientifica. 6 ed. São Paulo: Pearson Prentice Hall, 2007.
ENGECORPS - Corpo de Engenheiros Consultores S.A. Plano Municipal Integrado de Saneamento Básico, Município de Sorocaba. São Paulo, 2011. Disponível em <http://www.saneamento.sp.gov.br/PMS/UGRHI10/PM S_SOROCABA.pdf>. Acesso em: 20 de Agosto de 2014.

FERREIRA, Luiz Henrique (org.). Sustentabilidade nas Obras e nos Projetos: Questões Práticas para Profissionais e Empresas. São Paulo: PINI, 2012. 107 p.

GIL, Antonio Carlos. Como elaborar projetos de pesquisa. São Paulo: Editora Atlas, 2002.

JOHN, Vanderley M.; AGOPYAN, Vahan. Reciclagem de Resíduos da Construção. Seminário - Reciclagem de Resíduos Sólidos Domiciliares. São Paulo, 2000. Disponível em: <http://www.researchgate.net/ publication/228600228_Reciclagem_de_resduos_da_co nstruo/ffil/5046352af919c1984c.pdf $>$. Acesso em: 18 de Agosto de 2014.

KARPINSK, Luisete Andreis.et al Gestão Diferenciada de Resíduos da Construção Civil: Uma Abordagem Ambiental. Porto Alegre: Edipurcs, 2009. 163p.

MARINHO, Jefferson Luiz Alves; SILVA, Joel Dias. Gerenciamento dos resíduos da construção e demolição: diretrizes para o crescimento sustentável da construção civil na região metropolitana do cariri cearense. E-Tech: Tecnologias para competitividade industrial. Florianópolis, v. 5, n. 1, p. 102-119, 2012.

MARQUES NETO, José da Costa. Gestão dos resíduos de construção e demolição no Brasil. São Carlos: RiMa, 2005. 142p.

PINTO, Tarcísio de Paulo. Gestão ambiental de resíduos da construção civil: a experiência do SindusCon - SP. São Paulo: Obra Limpa. I\&T. SindusCon-SP, 2005. Disponível em: <http://www.sindusconsp.com.br/downloads/ prodserv/publicacoes/manual_residuos_solidos.pdf $>$. Acesso em: 03 nov. 2013.

PREFEITURA MUNICIPAL de Sorocaba. Plano de Gestão Integrada de Resíduos Sólidos: versão preliminar. Sorocaba, 2013. 84p.

Plano de Gerenciamento de Resíduos da Construção Civil do Município de Sorocaba - SP. Sorocaba, 2012. 33 p.

SANEX - Soluções Ltda. Avaliação, Diagnóstico e Proposição de Soluções visando à Elaboração do Plano Municipal de Resíduos Inertes e Recicláveis do Município de Sorocaba. Sorocaba. 2011, 352 pg.

SHS - Consultoria e Projetos de Engenharia Ltda. Plano Municipal de Gestão Integrada de Resíduos Sólidos de Sorocaba - SP - Versão Preliminar. Sorocaba/SP. 2014 Disponível em: < http://www.meioambientesorocaba. com.br/sema/UserFiles/file/Residuos\%202014/Relat\%C 3\%B3rio\%20R-3\%20PMGIRS.pdf> . Acesso em: 06 nov. 2014. 
SOROCABA. Câmara Municipal. Lei no 8.614, de 15 de dezembro de 2008. Dispõe sobre a criação e o uso do aterro municipal de resíduos inertes e dá outras providências. Disponível em < http://camara-municipalda-sorocaba.jusbrasil.com.br/legislacao/523410/lei-

8614-08>. Acesso em: 15 out. 2014.

ZORDAN, Sergio Eduardo. A utilização do entulho como agregado na confecção do concreto. 1997. 140 f.

Dissertação (Mestrado em Engenharia Civil). Departamento de Saneamento e Meio Ambiente da Faculdade de Engenharia Civil, Universidade Estadual de Campinas, Campinas. 1997. 